\title{
Inhibitory Effects of Several Spices on Inflammation Caused by Advanced Glycation Endproducts
}

\author{
Su-Chen Ho, Pei-Wen Chang \\ Department of Food Science, Yuanpei University, Hsinchu, Chinese Taipei. \\ Email: sche@mail.ypu.edu.tw
}

Received April 17 $7^{\text {th }}, 2012$; revised May 16 ${ }^{\text {th }}, 2012$; accepted June $5^{\text {th }}, 2012$

\begin{abstract}
Advanced glycation endproducts (AGEs) is implicated in the pathogenesis of diabetic complications. Inhibiting the formation of AGEs and interfering with AGEs-mediated inflammation are two practicable strategies for developing a dietary adjuvant against diabetic complications. This study evaluated the protective capacities against diabetic complications of several spices based on their inhibition of the formation of AGEs in an in vitro BSA/glucose system and on the AGEs-induced production of proinflammatory cytokine in RAW 264.7 macrophages. Among the tested spices, cinnamon exhibited most strongly inhibited both the formation of AGEs and the AGEs-induced production of nitric oxide, interleukin- 6 and tumor necrosis factor- $\alpha$. Additionally, correlative results revealed that the capacity of spices to inhibit the formation of AGEs is attributable to phenolic compounds and, in contrast, the capacity to inhibit AGEs-induced inflammation is attributable to condensed tannin. This investigation demonstrates the potential of cinnamon to serve as a dietary adjuvant against diabetic complications.
\end{abstract}

Keywords: Advanced Glycation End-Products; Diabetic Complication; Inflammation; Spices

\section{Introduction}

During recent decades, growing evidence has shown that advanced glycation end-products (AGEs) participate importantly the pathogenesis of diabetic complications $[1,2]$. AGEs are a group of deleterious heterogeneous end products of nonenzymatic glycation. Covalent modification of protein and induction of oxidative stress and inflammatory response are two well-known deleterious effects of AGEs. Proteins, particularly those long-lived extracellular matrix molecules, when covalently crosslinked with AGEs result in undergo a structural change and exhibit functional abnormality [1]. Secondly, AGEs can disrupt cellular function by binding to specific cell surface receptors. One of the most extensively studied receptors is the receptor for AGEs (RAGE). The engagement of AGEs with RAGE triggers NADPH-oxidase, increasing intracellular oxidative stress, evoke signaling pathways such as protein kinase $\mathrm{C}$, mitogen-activated protein kinase and the extracellular signal regulated kinase; activate transcription factor NF- $\mathrm{KB}$ and AP-1, and subsequently induce thrombogenic, fibrogenic, adhesive, chemoattractive and proinflammatory gene expression [3]. This AGEs-induced oxidative stress, fibrosis and inflammation accelerate the progress of diabetic vascular complications [4]. Accordingly, the inhibition of
AGE formation (anti-glycation), the blocking of AGERAGE interactions, and the suppression of RAGE expression or its downstream pathways have potential for use in therapeutic interventions against diabetic vascular complications. Indeed, agents that block the formation of AGEs, including aminoguanidine, thiamine and pyridoxine, and those that suppress AGEs-induced inflammation such as secreted form of RAGE (sRAGE), which blocks RAGE, have yielded promising results in animal models [5].

Spices that are rich in phytochemicals with anti-oxidant, anti-inflammatory, anti-carcinogenic, anti-microbial, hypolipidemic and other beneficial physiological properties, are extensively used in folk medicines for treating numerous chronic diseases and diabetes [6]. Although the beneficial effects of spices on diabetes have been studied for a long time, most researchers have focused on their hypoglycemic effect. The possible protective effects of spices against diabetic complications, especially regarding AGEs-induced inflammation, are few. It has been showed that AGEs can activate monocytes/macrophages to secret many chemoattractive and proinflammatory cytokines such as IL-1, IL-6, TNF- $\alpha$ and the inducible nitric oxide synthase (iNOS) by activation of transcription factor, NF- $\kappa B[7,8]$. To this end, in this investigation, the protective properties of several culinary spices against 
diabetic complications were determined from studying their capacity to inhibit the formation of AGEs in vitro and to inhibit AGEs-induced production of proinflammatory mediators such as nitric oxide (NO), interleukin-6 (IL-6) and tumor necrosis factor- $\alpha$ (TNF- $\alpha$ ) in RAW 264.7 macrophages.

\section{Materials and Methods}

\subsection{Chemicals Used}

Folin-Ciocalteu phenol reagent, catechin, gallic acid, dimethyl sulfoxide (DMSO), bovine serum albumin (BSA), D-glucose, aminoguanidine, sulphanilamide, naphthylethylenediamine, 3-(4,5-dimethyldiazol-2-yl)-2,5 diphenyl tetrazolium bromide (MTT) and nitro blue tetrazolium chloride/5-bromo-4-chloro-3-indolyl phosphate p-toluidine salt (NBT/BCIP) tablets were purchased from Sigma Chemical Co. (St. Louis, MO, USA). All chemicals were analytical grade.

\subsection{Preparation of Spice Extract}

All of the tested dried spices were commercial products of Tomax Co. (Taiwan) and purchased from a local supermarket (Hsinchu, Taiwan) in the winter of 2009. Extraction was conducted by mixing $10 \mathrm{~g}$ of the dried spice powder with $300 \mathrm{ml}$ methanol in a glass flask and then shaking violently $(100 \mathrm{rpm})$ at $37^{\circ} \mathrm{C}$ for $20 \mathrm{~h}$. After the suspension had been filtered through No. 2 filters, the filtrate was evaporated under a vacuum at a temperature of lower than $50^{\circ} \mathrm{C}$ to remove the methanol. Finally, the extracted solids were weighed and dissolved in DMSO.

\subsection{Determination of Phenolic Compound, Flavonoid and Condensed Tannin}

The Folin-Ciocalteu colorimetric approach and the aluminium chloride colorimetric method were utilized to measure the concentration of phenolic compounds and flavonoid in the spice extracts, respectively [9]. The content of condensed tannin was determined by using vanillin method according to a previous literature [10].

\subsection{Evaluation of Antiglycating Capacity of Spice Extracts}

An in vitro BSA/glucose glycation system of Vinson \& Howard was adopted [11]. Briefly, spice extracts or aminoguanidine were incubated with $20 \mathrm{mg} / \mathrm{ml} \mathrm{BSA}$, $500 \mathrm{mM}$ glucose and $0.02 \%(\mathrm{w} / \mathrm{v})$ sodium azide in phosphate buffer $(100 \mathrm{mM}, \mathrm{pH} 7.4)$ at $37^{\circ} \mathrm{C}$ for 3 weeks. The fluorescent intensity was measured using a fluorescent spectrometer with exciting and emission wavelengths of 330 and $410 \mathrm{~nm}$, respectively. The antiglycating capacity (\%) of spice extract was calculated as the difference be- tween the fluorescent intensity of the spice glycation solution with glucose and that without glucose as a proportion of the difference between the fluorescent intensity of DMSO glycation solution with glucose and that without glucose.

\subsection{Preparation of AGEs-Modified Albumins Used in Cell Culture}

The AGEs-modified albumins that were used in cell culture experiments were prepared following the method of Berbaum et al. [7].

\subsection{Cell Culture Experiment}

RAW 264.7 macrophages were obtained from Bioresource and BioResearch Center (Hsinchu, Taiwan) and cultured in DMEM medium that was supplemented with $10 \%$ fetal bovine serum (Invitrogen, Carlsbad, CA, USA). $1 \times 105$ cells were seeded into each well of a 96-well culture plate and cultured overnight. After washing with PBS, medium with spice extract and AGEs-modified albumins were added and the system was incubated for $24 \mathrm{~h}$. The negative control presents the cells without any treatment. The cells which only treated with AGEsmodified albumins were assigned as positive control. The conditioned medium was collected, and the cell viability was evaluated by the MTT method.

\subsection{Measurement of Amounts of Secreted NO, IL-6 and TNF- $\alpha$}

Nitrite concentration as an indicator of NO production was measured using the Griess reagent. The concentrations of IL- 6 and TNF- $\alpha$ in the conditioned medium were measured using commercial ELISA kits (eBioscience, San Diego, CA, USA) following the manufacturer's instructions.

\subsection{Measurement of Protein Levels of Inducible Nitric Oxide Synthase (iNOS)}

After incubation with spice extract and AGEs-modified albumins for $12 \mathrm{~h}$, the adherent cells were washed with PBS, collected, suspended in the lysis buffer $(50 \mathrm{mM}$ Tris, $\mathrm{pH} 7.6,0.01 \%$ ethylenediaminetetraacetic acid (EDTA), 1\% Triton X-100, $1 \mathrm{mM}$ phenylmethanesulfonyl fluoride, and $1 \mu \mathrm{g} / \mathrm{ml}$ leupeptin) and centrifuged at $12,000 \times \mathrm{g}$ for $20 \mathrm{~min}$ at $4^{\circ} \mathrm{C}$. The protein level of cellular iNOS was determined by western blotting and normalized to $\beta$-actin as described previously [12].

\subsection{Measurement of mRNA Levels of iNOS}

After they had been incubated with $200 \mu \mathrm{g} / \mathrm{ml}$ spice extract and $1 \mathrm{mg} / \mathrm{ml}$ AGEs-modified albumins for $6 \mathrm{~h}$, ad- 
herent cells were collected and the total RNA was isolated using Trizol reagent (Invitrogen, Carlsbad, CA, USA). The mRNA level of iNOS was determined using the reverse transcription polymerase chain reaction and performed as described previously [12].

\subsection{Statistical Analysis}

All experimental results are expressed as mean \pm SD from three independent tests. The significance of the differences between treatments was evaluated by ANOVA, and then Duncan's multiple range test was performed to make multiple comparisons. The condition for significance of the difference between datasets was $p<0.05$. The correlation between two variants was analyzed by performing the Pearson test. All statistical analyses were conducted using SPSS software (SPSS 12.0 for Windows; SPSS Inc., Chicago, IL, USA).

\section{Results}

\subsection{Concentration of Phenolic Compound, Flavonoid, and Condensed Tannin}

As listed in Table 1, the amounts of phenolic compounds in different spice extracts varied considerably. Cinnamon extract contained the most abundant phenolic compounds, whereas cumin and parsley extracts contained the least phenolic compounds. The amounts of flavonoid and condensed tannin varied significantly. Thyme contained the most flavonoid. Cumin contained the least-only 1.1 $\mathrm{mg} \mathrm{CEs} / \mathrm{g}$, or roughly $1.8 \%$ of that in thyme. Cinnamon, cumin and rosemary contained more than $10 \mathrm{mg} \mathrm{CEs} / \mathrm{g}$, and were rich in condensed tannin. The concentration of condensed tannin in cardamom extract was lower than the detection limit.

\subsection{Anti-Glycating Capacities of Spice Extracts}

As listed in Table 2, aminoguanidine, a well-known in- hibitor of the formation of AGEs, exhibited complete inhibition at concentrations over $100 \mu \mathrm{g} / \mathrm{ml}$ and exhibited $74.4 \%$ inhibition of the formation of fluorescent AGEs at a concentration of $50 \mu \mathrm{g} / \mathrm{ml}$. All spice extracts suppressed the glucose-mediated formation of fluorescent AGEs in a dose-dependent manner at concentrations of $50-200 \mu \mathrm{g} / \mathrm{ml}$. For ease of comparison, the IC50, which is the concentration required to inhibit the formation of fluorescent AGEs by $50 \%$, was calculated. The antiglycating capacities of the spice extracts, given by IC50 declined in the order; cinnamon, thyme, turmeric, rosemary, basil, parsley, cumin and cardamom.

\subsection{Effects of Spice Extracts on AGEs-Stimulated Secretion of NO, IL-6 and TNF- $\alpha$}

The viabilities of all cells that were treated with any of the spices exceeded $95 \%$ of that of the DMSO control group (data not shown). This result indicated that the spice extracts at the concentrations $(50-200 \mu \mathrm{g} / \mathrm{ml})$ used herein were not cytotoxic. Figure 1 presents the effect of the spice extracts on the AGEs-induced secretion of NO. As described elsewhere [7,8], treating RAW 264.7 macrophages with AGEs-modified albumins (1 mg/ml) induced substantial NO secretion. Additionally, cotreatment of the cells with AGEs-modified albumins and various concentrations of the spice extracts significantly inhibited NO production in a concentration-dependent manner. Based on the results obtained at a concentration of $200 \mu \mathrm{g} / \mathrm{ml}$, the capacities of the different spice extracts to inhibit the AGEs-induced secretion of NO declined in the order; cinnamon, rosemary, cumin, thyme, basil, turmeric, cardamom and parsley. The inhibition by spice extracts of IL- 6 and TNF- $\alpha$ secretion was weak at treatment concentrations of less than $200 \mu \mathrm{g} / \mathrm{ml}$, so only the results of treatment at concentration of $200 \mu \mathrm{g} / \mathrm{ml}$ are presented in Figure 2. All of the tested spice extracts

Table 1. Concentrations of phenolic compound, flavonoid and condensed tannin.

\begin{tabular}{ccccc}
\hline Common name & Botanical name & $\begin{array}{c}\text { Phenolic } \\
(\mathrm{mg} \mathrm{GAEs} / \mathrm{g} \text { extract })\end{array}$ & $\begin{array}{c}\text { Flavonoid } \\
(\mathrm{mg} \text { CEs/g extract) }\end{array}$ & $\begin{array}{c}\text { Condensed tannin } \\
\text { (mg CEs/g extract) }\end{array}$ \\
\hline $\begin{array}{c}\text { Basil } \\
\text { Cardamom }\end{array}$ & Ocimum basilicum & $68.9 \pm 1.0^{\mathrm{d}}$ & $24.8 \pm 0.3^{\mathrm{d}}$ & $9.3 \pm 1.9^{\mathrm{bcd}}$ \\
Elettaria cardamomum & $69.7 \pm 1.1^{\mathrm{d}}$ & $11.6 \pm 0.6^{\mathrm{e}}$ & $\mathrm{ND}^{\mathrm{a}}$ \\
Cumin & Cinnamomum verum & $226.7 \pm 7.0^{\mathrm{a}}$ & $59.7 \pm 2.2^{\mathrm{b}}$ & $14.7 \pm 7.2^{\mathrm{d}}$ \\
Parsley & Cuminum cyminum & $39.4 \pm 1.8^{\mathrm{e}}$ & $1.1 \pm 0.0^{\mathrm{f}}$ & $12.5 \pm 2.3^{\mathrm{cd}}$ \\
Rosemary & Petroselinum crispum & $45.1 \pm 1.0^{\mathrm{e}}$ & $2.5 \pm 0.1^{\mathrm{f}}$ & $6.5 \pm 2.2^{\mathrm{abc}}$ \\
Thyme & Rosmarinus officinalis & $93.6 \pm 0.3^{\mathrm{c}}$ & $41.2 \pm 1.7^{\mathrm{c}}$ & $12.0 \pm 1.0^{\mathrm{cd}}$ \\
Turmeric & Thymus vulgaris & $141.1 \pm 0.7^{\mathrm{b}}$ & $62.4 \pm 1.3^{\mathrm{a}}$ & $4.6 \pm 2.0^{\mathrm{ab}}$ \\
\hline
\end{tabular}

Means not sharing a common letter in the same column were significantly different $(p<0.05)$ when analyzed by ANOVA and Duncan's multiple range test. 
Table 2. Antiglycating capacities of spice extracts.

\begin{tabular}{ccccc}
\hline \multirow{2}{*}{ Treating conc. } & \multicolumn{3}{c}{ Inhibitory capacity $(\%)$} & \multirow{2}{*}{$\mathrm{IC}_{50}(\mu \mathrm{g} / \mathrm{mL})$} \\
\cline { 2 - 4 } & $200 \mu \mathrm{g} / \mathrm{mL}$ & $100 \mu \mathrm{g} / \mathrm{mL}$ & $50 \mu \mathrm{g} / \mathrm{mL}$ & 83.7 \\
\hline Basil & $80.7 \pm 0.9^{\mathrm{d}}$ & $59.2 \pm 1.1^{\mathrm{d}}$ & $37.5 \pm 2.0^{\mathrm{d}}$ & 129.5 \\
Cardamom & $68.6 \pm 0.9^{\mathrm{f}}$ & $45.7 \pm 2.6^{\mathrm{e}}$ & $24.7 \pm 1.5^{\mathrm{f}}$ & 26.0 \\
Cinnamon & $99.3 \pm 1.4^{\mathrm{a}}$ & $88.7 \pm 1.4^{\mathrm{a}}$ & $62.6 \pm 1.1^{\mathrm{a}}$ & 111.6 \\
Cumin & $81.6 \pm 0.9^{\mathrm{d}}$ & $48.9 \pm 2.0^{\mathrm{e}}$ & $25.2 \pm 1.1^{\mathrm{f}}$ & 99.1 \\
Parsley & $74.5 \pm 1.5^{\mathrm{e}}$ & $57.7 \pm 5.0^{\mathrm{d}}$ & $31.9 \pm 1.4^{\mathrm{e}}$ & 58.8 \\
Rosemary & $91.1 \pm 1.9^{\mathrm{b}}$ & $69.0 \pm 0.4^{\mathrm{c}}$ & $46.0 \pm 1.8^{\mathrm{c}}$ & 44.2 \\
Thyme & $94.9 \pm 0.3^{\mathrm{b}}$ & $78.1 \pm 1.3^{\mathrm{b}}$ & $52.9 \pm 3.9^{\mathrm{b}}$ & 50.6 \\
Turmeric & $89.9 \pm 0.6^{\mathrm{c}}$ & $72.4 \pm 0.5^{\mathrm{c}}$ & $49.7 \pm 0.3^{\mathrm{b}}$ & \\
& $800 \mu \mathrm{M}$ & $400 \mu \mathrm{M}$ & $200 \mu \mathrm{M}$ & - \\
\hline
\end{tabular}

Means not sharing a common letter in the same column were significantly different $(p<0.05)$ when analyzed by ANOVA and Duncan's multiple range test.

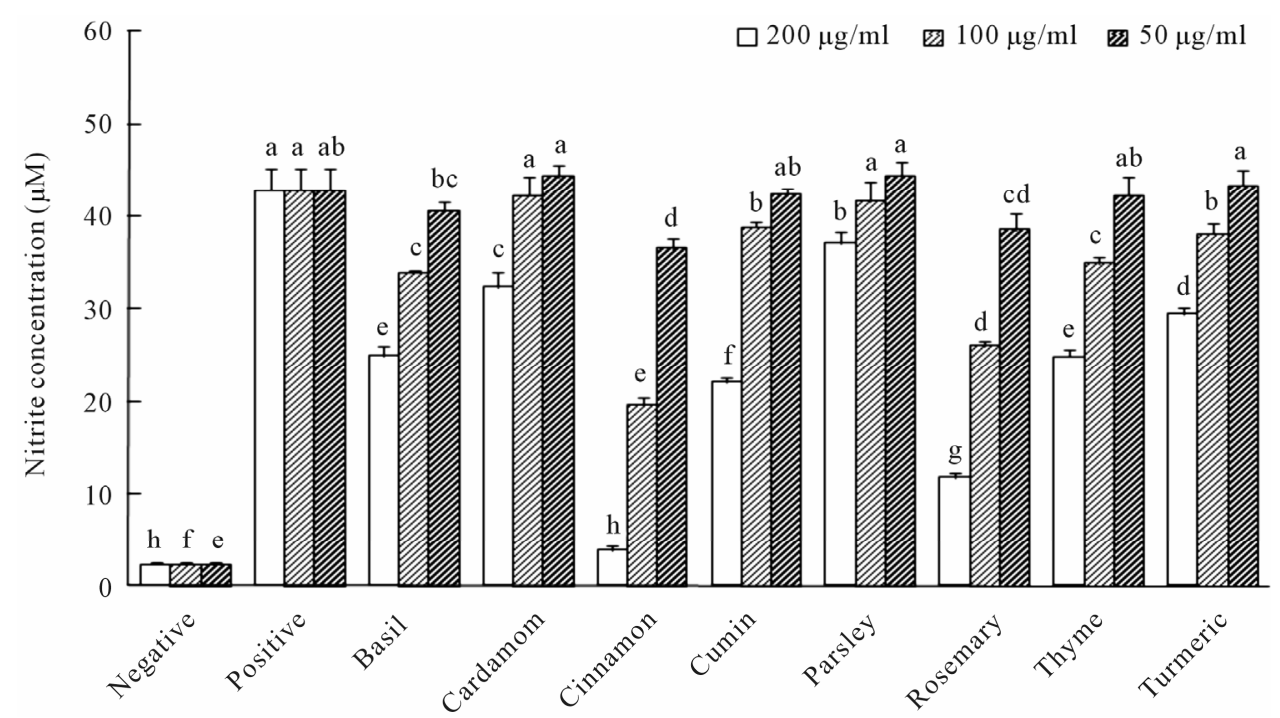

Figure 1. Effect of spice extracts on NO production in AGE-stimulated RAW264.7 cells.

significantly inhibited IL-6 secretion. Cinnamon almost completely inhibited AGEs-induced IL-6 secretion and was the most potent of the tested spices. Spice extracts had less of a capacity to inhibit AGEs-stimulated TNF- $\alpha$ secretion in RAW264.7 macrophages than they did to inhibit the secretion of NO and IL-6. Similarly, cinnamon was the most effective inhibitor of AGEs-stimulated $\mathrm{TNF}-\alpha$ secretion.

\subsection{Effects of Spice Extracts on Protein and mRNA Levels of iNOS in AGEs-Stimulated RAW264.7 Cells}

To investigate the mechanism of the inhibition by the spice extract on AGEs-induced NO secretion, the protein and mRNA levels of iNOS were evaluated. As shown in
Figure 3, AGEs-modified albumins induced significant expression of iNOS protein in RAW264.7 cells (positive) and except for cardamom, this expression was attenuated by co-incubation with spice extracts. At a concentration of $200 \mu \mathrm{g} / \mathrm{ml}$, the capacities of the spice extracts to inhibit the expression of iNOS protein declined in the order cinnamon, rosemary, cumin, thyme, basil, parsley and turmeric. Similarly, AGEs-modified albumins induced iNOS mRNA expression, which was inhibited by spice extracts. As expected, the amounts of $\mathrm{NO}$ secreted were strongly correlated with iNOS protein levels $(\mathrm{r}=0.849, p$ $=0.008)$ and the iNOS mRNA levels $(r=0.794, p=$ $0.019)$. These results indicated that spice extracts inhibited NO secretion mostly by down-regulating gene expression of iNOS. 


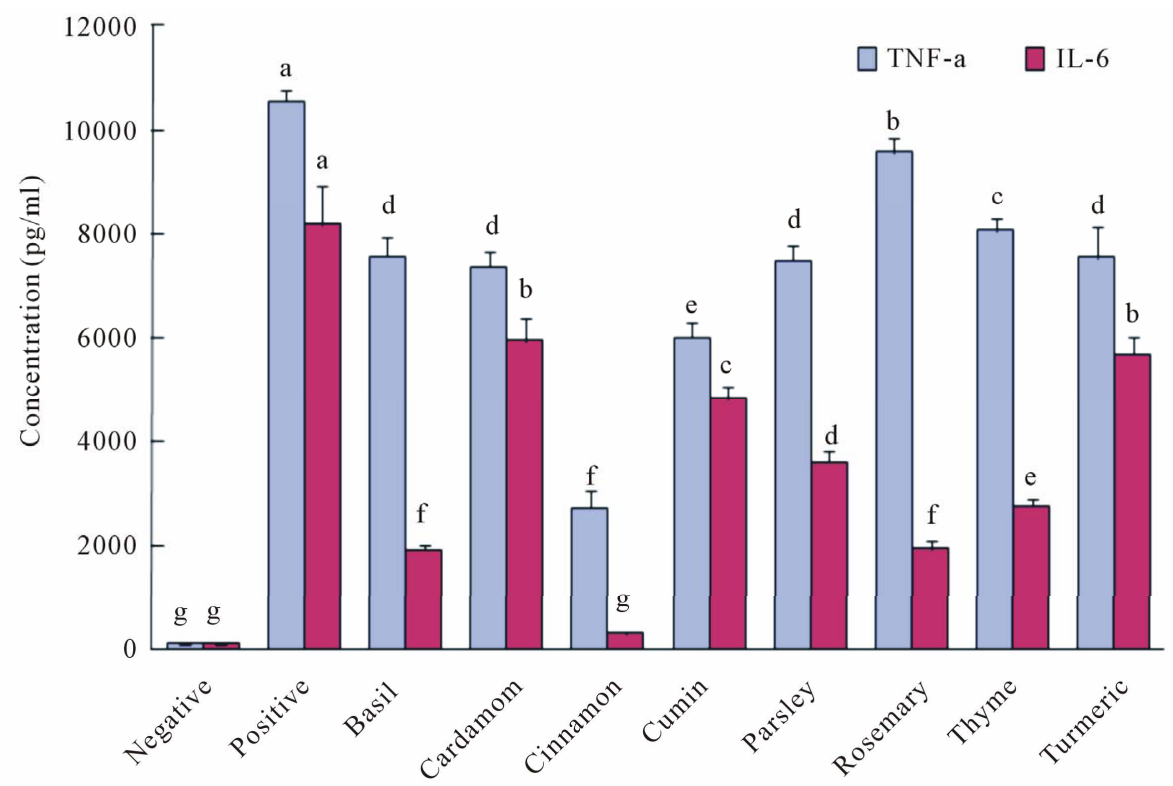

Figure 2. Effect of spice extracts on TNF- $\alpha$ and IL-6 production in AGE-stimulated RAW264.7 cells.

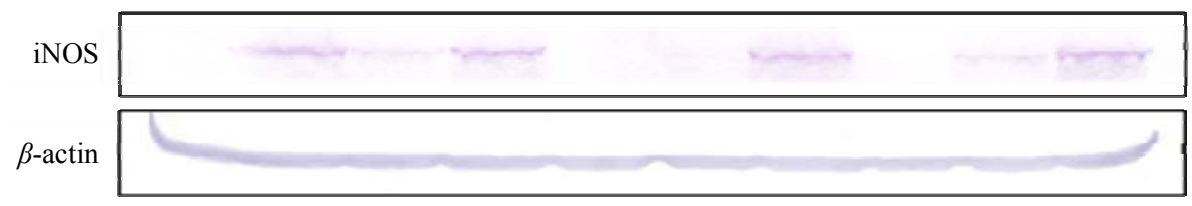

(a)

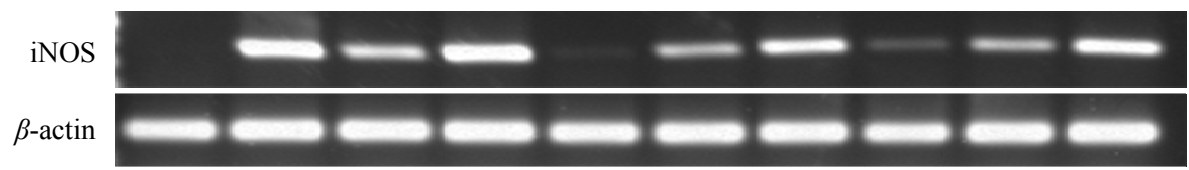

(b)

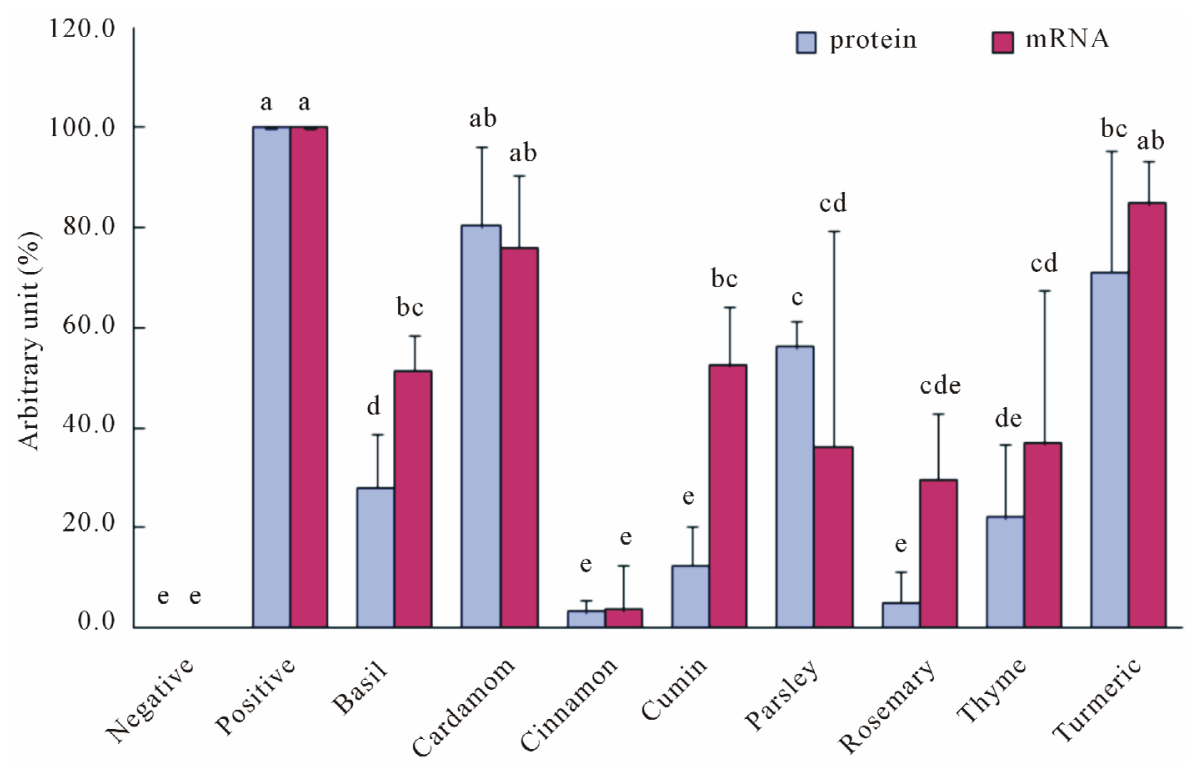

(c)

Figure 3. Effect of spice extracts on protein and mRNA levels of iNOS in AGE-stimulated RAW264.7 cells. (a) Protein levels; (b) mRNA levels; (c) Quantitative results. 


\subsection{Correlative Analysis}

The concentrations of both phenolic compound $(\mathrm{r}=$ $0.922, p=0.001)$ and flavonoid $(\mathrm{r}=0.943, p<0.001)$ in a particular spice extract were significantly correlated with its antiglycating capacity. However, interestingly, the concentration of condensed tannin in a particular spice extract was correlated with its capacity to inhibit the AGEs-induced production of NO $(\mathrm{r}=0.852, p=$ $0.007)$ and IL-6 $(\mathrm{r}=0.736, p=0.037)$.

\section{Discussion}

In this investigation, all eight of the tested spices inhibited the formation of AGEs in vitro to varying degrees, and their antiglycating capacities were correlated with the concentration of the phenolic compound. Consistent with earlier studies [13], the result supports the hypothesis that antioxidant phenolic compounds contribute to the antiglycation capacity of spices to an extent that depends strongly on their amount. Among the tested spices, cinnamon most strongly inhibited the formation of AGEs. The mechanisms by which cinnamon inhibits the formation of AGEs include antioxidation and the trapping of reactive carbonyl species [14]. Due to concern of safety, the evaluation and development of dietary inhibitors of the formation of AGEs has become an important trend in food research. Saraswat et al. [15] recently evaluated 17 dietary plants with strong antioxidant properties and found that three spices-ginger, cumin and cinnamonexhibited marked antiglycation activity, and could reduce the formation of different AGEs in vitro. Additionally, the antiglycating property of spices has been demonstrated in vivo and suggested to be responsible for the slowing of the development of diabetic complications [16]. For example, cumin has been shown to inhibit glycation and maintain the chaperone activity of $\alpha$-crystallin, and thereby, to delay the progress of cataract in diabetic rats [17].

More importantly, in this investigation, spices were found also to inhibit the AGEs-induced production of NO, IL- 6 and TNF- $\alpha$. Of the tested spices, cinnamon, rosemary and cumin were the most effective inhibitors thereof. The amounts of condensed tannin in the tested spices correlated significantly with the capacities of the spices to inhibit the AGEs-induced production of $\mathrm{NO}$ and IL-6. This result implies that the inhibition by spices of AGEs-induced inflammatory response primarily involved condensed tannin. Berbaum et al. [7] indicated that AGEs and lipopolysaccharide (LPS) follow similar or convergent downstream signaling pathways to induce the expression of proinflammatory genes in RAW264.7 macrophages. Indeed, in the authors' earlier investigation, spices were shown to reduce the production of $\mathrm{NO}$ and the expression of iNOS in LPS-activated RAW264.7 macrophages [18]. Additionally, based on the previous studies, the possible active components present in spices could be reasonably posited. Trans-cinnamaldehyde has been proven to be the active component that was responsible for the anti-inflammatory activity of cinnamon methanolic extract by considering the LPS-induced production of NO in RAW264.7 macrophages as an inflammatory model [19]. Based on the same model, carnosic acid and carnosol were identified as major contributors to the anti-inflammatory activity of rosemary [20]. Thymoquinone has been proposed to be the main anti-inflammatory component of cumin [21]. However, further work must be done to identify the components that are responsible for the inhibiting activity of spices toward the AGEs-induced inflammatory response. Based on our preliminary study, trans-cinnamaldehyde seems to be the most likely candidate component that is responsible for the potent inhibitory activity of cinnamon (data not shown).

In the past, owing to a lack of understanding of the biochemistry of AGEs and its relationship to diabetic complications, the protective effects of spices against diabetes have been studied mostly with reference to their hypoglycemic activity. Information regarding whether spices can protect against diabetic complications has heretofore been scant. Recently, cumin, ginger, turmeric and cinnamon have been reported to help treat cataract and nephropathy in diabetic rats [22-25]. Turmeric and its constituent, curcumin, can delay the development of a cataract but does not have any effect on blood glucose [25]. Clearly, as well as having a hypoglycemic capacity, spices can protect against diabetic complications in other ways.

\section{Conclusion}

In this investigation, very interestingly, cinnamon exhibited the strongest capacity not only to inhibit the formation AGEs but also to inhibit the AGEs-mediated inflammatory response. Although a definitive conclusion concerning the use of cinnamon as a hypoglycemic agent cannot yet be drawn, cinnamon has been extensively used as an anti-diabetic supplement since its hypoglycemic activity was reported in 2003 [26]. The results herein suggest the possible application of cinnamon in the primary and secondary prevention of diabetic complications, based on its potent inhibition of the formation of AGEs and of AGEs-mediated inflammation.

\section{Acknowledgements}

The authors would like to thank the National Science Council of the Republic of China, Taiwan, for financially supporting this research under Contract No. NSC 972320-B-264-001-MY3. 


\section{REFERENCES}

[1] M. Brownlee, "Biochemistry and Molecular Cell Biology of Diabetic Complications," Nature, Vol. 414, No. 6865, 2001, pp. 813-820. doi:10.1038/414813a

[2] N. Ahmed, "Advanced Glycosylation End ProductsRole in Pathology of Diabetic Complications," Diabetes Research and Clinical Practice, Vol. 67, No. 1, 2005, pp. 3-21. doi:10.1016/j.diabres.2004.09.004

[3] R. Clynes, B. Moser, S. F. Yan, R. Ramasamy, K. Herold and A. M. Schmidt, "Receptor for AGE (RAGE): Weaving Tangled Webs within the Inflammatory Response," Current Molecular Medicine, Vol. 7, No. 8, 2007, pp. 743-751. doi:10.2174/156652407783220714

[4] G. Basta, "Receptor for Advanced Glycation Endproducts and Atherosclerosis: From Basic Mechanisms to Clinical Implications," Atherosclerosis, Vol. 196, No. 1, 2008, pp. 9-21. doi:10.1016/j.atherosclerosis.2007.07.025

[5] M. Takeuchi, J.-I. Takino and S.-I. Yamagishi, "Involvement of the Toxic AGEs (TAGE)-RAGE System in the Pathogenesis of Diabetic Vascular Complications: A Novel Therapeutic Strategy," Current Drug Targets, Vol. 11, No. 11, 2010, pp. 1468-1482.

[6] K, Srinivasan, "Role of Spices beyond Food Flavoring: Nutraceuticals with Multiple Health Effects," Food Reviews International, Vol. 21, No. 2, 2005, pp. 167-188. doi:10.1081/FRI-200051872

[7] K. Berbaum, K. Shanmugam, G. Stuchbury, F. Wiede, H. Korner and G. Munch, "Induction of Novel Cytokines and Chemokines by Advanced Glycation Endproducts Determined with a Cytometric Bead Array," Cytokine, Vol. 41, No. 3, 2008, pp. 198-203. doi:10.1016/j.cyto.2007.11.012

[8] C.-H. Wu, C.-M. Huang, C.-H. Lin, Y.-S. Ho, C.-M. Chen and H.-M. Lee, "Advanced Glycosylation End Products Induce NF- $\mathrm{B}$ Dependent iNOS Expression in RAW 264.7 Cells," Molecular and Cellular Endocrinology, Vol. 194, No. 1-2, 2002, pp. 9-17. doi:10.1016/S0303-7207(02)00212-5

[9] Y. Okada, M. Okada and Y. Sagesaka, "Screening of Dried Plant Seed Extracts for Adiponectin Production Activity and Tumor Necrosis Factor-Alpha Inhibitory Activity on 3T3-L1 Adipocytes," Plant Foods for Human Nutrition, Vol. 65, No. 3, 2010, pp. 225-232. doi:10.1007/s11130-010-0184-2

[10] S. Toda, "Antioxidative Effects of Polyphenols in Leaves of Houttuynia cordata on Protein Fragmentation by Copper-Hydrogen Peroxide in Vitro," Journal of Medicinal Food, Vol. 8, No. 2, 2005, pp. 266-268. doi:10.1089/jmf.2005.8.266

[11] J. A. Vinson and H. B. Howard III, "Inhibition of Protein Glycation and Advanced Glycation End Products by Ascorbic Acid and Other Vitamins and Nutrients," Journal of Nutritional Biochemistry, Vol. 7, No. 12, 1996, pp. 659-663. doi:10.1016/S0955-2863(96)00128-3

[12] Y.-S. Huang and S.-C. Ho, "Polymethoxy Flavones Are Responsible for the Anti-Inflammatory Activity of Citrus Fruit Peel," Food Chemistry, Vol. 119, No. 3, 2010, pp. 868-873. doi:10.1016/j.foodchem.2009.09.092
[13] R. P. Dearlove, P. Greenspan, D. K. Hartle, R. B. Swanson and J. L. Hargrove, "Inhibition of Protein Glycation by Extracts of Culinary Herbs and Spices," Journal of Medicinal Food, Vol. 11, No. 2, 2008, pp. 275-281. doi:10.1089/jmf.2007.536

[14] X. Peng, K.-W. Cheng, J. Ma, B. Chen, C.-T. Ho, C. Lo, F. Chen and M. Wang, "Cinnamon Bark Proanthocyanidins as Reactive Carbonyl Scavengers to Prevent the Formation of Advanced Glycation Endproducts," Journal of Agricultural and Food Chemistry, Vol. 56, No. 6, 2008, pp. 1907-1911. doi:10.1021/jf073065v

[15] M. Saraswat, P. Y. Reddy, P. Muthenna and G. B. Reddy, "Prevention of Non-Enzymatic Glycation of Proteins by Dietary Agents: Prospects for Alleviating Diabetic Complications," British Journal of Nutrition, Vol. 101, No. 11, 2009, pp. 1714-1721. doi:10.1017/S0007114508116270

[16] A. G. Jagtap and P. B. Patil, “Antihyperglycemic Activity and Inhibition of Advanced Glycation End Product Formation by Cuminum cyminum in Streptozotocin Induced Diabetic Rats," Food and Chemical Toxicology, Vol. 48, No. 8-9, 2010, pp. 2030-2036. doi:10.1016/i.fct.2010.04.048

[17] P. A. Kumar, P. Y. Reddy, P. N. B. S. Srinivas and G. B. Reddy, "Delay of Diabetic Cataract in Rats by the Antiglycating Potential of Cumin through Modulation of $\alpha$-crystallin Chaperone Activity," Journal of Nutritional Biochemistry, Vol. 20, No. 7, 2009, pp. 553-562. doi:10.1016/j.jnutbio.2008.05.015

[18] P.-J. Tsai, T.-H. Tsai, C.-H. Yu and S.-C. Ho, "Evaluation of NO-Suppressing Activity of Several Mediterranean Culinary Spices," Food and Chemical Toxicology, Vol. 45, No. 3, 2007, pp. 440-447. doi:10.1016/j.fct.2006.09.006

[19] H. S. Lee, B. S. Kim and M. K. Kim, "Suppression Effect of Cinnamomum cassia Bark-Derived Component on Nitric Oxide Synthase," Journal of Agricultural and Food Chemistry, Vol. 50, No. 26, 2002, pp. 7700-7703. doi:10.1021/jf020751f

[20] N. Bai, K. He, M. Roller, C.-S. Lai, X. Shao, M.-H. Pan and C.-T. Ho, "Flavonoids and Phenolic Compounds from Rosmarinus officinalis," Journal of Agricultural and Food Chemistry, Vol. 58, No. 9, 2010, pp. 5363-5367. doi:10.1021/jf100332w

[21] V. Hajhashemi, A. Ghannadi and H. Jafarabadi, "Black Cumin Seed Essential Oil, as a Potent Analgesic and Antiinflammatory Drug," Phytotheraphy Research, Vol. 18, No. 3, 2004, pp. 195-199. doi:10.1002/ptr.1390

[22] Z. M. Al-Amin, M. Thomson, K. K. Al-Qattan, R. Peltonen-Shalaby and M. Ali, "Anti-Diabetic and Hypolipidaemic Properties of Ginger (Zingiber officinale) in Streptozotocin-Induced Diabetic Rats," British Journal of Nutrition, Vol. 96, No. 4, 2006, pp. 660-666. doi:10.1079/BJN20061849

[23] S. Sharma, S. K. Kulkarni and K. Chopra, "Curcumin, the Active Principle of Turmeric (Curcuma longa), Ameliorates Diabetic Nephropathy in Rats," Clinical and Experimental Pharmacology and Physiology, Vol. 33, No. 10, 2006, pp. 940-945.

doi:10.1111/j.1440-1681.2006.04468.x 
[24] Y. Shen, M. Fukushima, Y. Ito, E. Muraki, T. Hosono, T. Seki and T. Ariga, "Verification of the Antidiabetic Effects of Cinnamon (Cinnamomum zeylanicum) Using Insulin-Nncontrolled Type 1 Diabetic Rats and Cultured Adipocytes," Bioscience, Biotechnology, and Biochemistry, Vol. 74, No. 12, 2010, pp. 2418-2425. doi:10.1271/bbb.100453

[25] P. Suryanarayana, M. Saraswat, T. Mrudula, T. P. Krishna, K. Krishnaswamy and G. B. Reddy, "Curcumin and Tur- meric Delay Streptozotocin-Induced Diabetic Cataract in Rats," Investigative Ophthalmology and Visual Science, Vol. 46, No. 6, 2005, pp. 2092-2099. doi:10.1167/iovs.04-1304

[26] S. Kirkham, R. Akilen, S. Sharma and A. Tsiami, "The Potential of Cinnamon to Reduce Blood Glucose Levels in Patients with Type 2 Diabetes and Insulin Resistance," Diabetes Obesity and Metabolism, Vol. 11, No. 12, 2009, pp. 1100-1113. doi:10.1111/j.1463-1326.2009.01094.x 